Gut, 1962, 3, 61

\title{
A 5-hydroxytryptophan-secreting carcinoid tumour
}

\author{
A. C. P. CAMPBEll, A. H. GOWENLOCK, D. S. PlAtT, \\ AND P. J. D. SNOW \\ From the Department of Pathology, University of Manchester, and \\ the Bolton Hospital Group
}

EDITORIAL SYNOPSIS An atypical case of the malignant carcinoid syndrome, associated with multiple peptic ulcers, is described. The tumour cells were argyrophil but not argentaffin, and the tumour was found to contain 5-hydroxytryptophan (5-H.T.P.) but not 5-hydroxytryptamine (5-H.T.). This aberrant biochemical behaviour was associated with the virtual absence of 5-H.T.P.decarboxylase from the tumour tissue. The tumour contained notable quantities of histamine.

The carcinoid syndrome is by now well known and has been shown to result from the liberation of 5-hydroxytryptamine by the tumour tissue. The diagnosis is usually confirmed by the detection in the urine of large quantities of 5-hydroxyindole-3-acetic acid (5-H.I.A.A.), the oxidation product of 5hydroxytryptamine. In most cases only insignificant quantities of other 5-hydroxyindoles are present in the urine, but in 1958 Sandler and Snow described a patient with a metastasizing carcinoid tumour whose urine contained not only 5-H.I.A.A. but relatively large quantities of 5-H.T. itself and its precursor, 5-hydroxytryptophan. Smith, Nyhus, Dalgliesh, Dutton, Lennox, and Macfarlane (1957), in reporting a similar case, suggested that these abnormal findings could be produced by a renal metastasis, but this possibility was excluded in Snow's case after specimens of urine obtained from each ureter were found to contain similar concentrations of all three indoles. As an alternative explanation Sandler and Snow suggested that the tumour might be secreting 5-H.T.P. rather than 5-H.T. but were unable to prove this hypothesis directly. It has now been possible to obtain samples of tumour tissue from this patient, and confirmation of the correctness of the hypothesis has been obtained.

The present paper describes the investigations carried out together with some additional and hitherto unpublished observations on this patient.

\section{CASE REPORT}

The patient, a man aged 48 at the time of his death in 1961, first attended the Out-patient Clinic at Manchester Royal Infirmary in January 1954, complaining of vaguely localized abdominal pain, anorexia, and vomiting. The symptoms had been present for two or three weeks and he had experienced a similar episode 12 months previously.

The liver was found to be enlarged three or four fingerbreadths below the costal margin and was hard. A barium meal study was carried out but showed no abnormality. In September of the same year he was admitted to hospital, having had further episodes of abdominal pain which was now epigastric. The clinical findings were as before but investigations, including liver function tests, revealed no abnormality and the patient was discharged without a firm diagnosis.

In March 1955 he again attended with similar complaints, and on this occasion was noticed to flush while being examined. On questioning he admitted that he had been subject to severe attacks of flushing for the past 20 years, occurring mainly with emotion, after meals, and especially with alcohol. The flushes were accompanied by only slight subjective changes and usually lasted from five to 20 minutes. The minor attacks were usually blotchy but in the more severe episodes the whole body flushed bright red. The liver enlargement was unchanged and no additional abnormalities were detected. The diagnosis of a carcinoid tumour was now considered and was supported by the detection of abnormal quantities of 5-H.I.A.A. in the urine. A laparotomy was performed at which the liver was found to be studded with multiple whitish tumours up to $3 \mathrm{~cm}$. in diameter. A white subserous tumour about $2 \mathrm{~cm}$. in diameter was present on the lesser curve of the stomach. Despite extensive exploration of the rest of the abdominal cavity no other tumour could be found and it was considered probable that the gastric lesion was the primary growth. An active chronic ulcer was present in the duodenum. Portions of the tumour tissue were biopsied and the histological diagnosis of carcinoid tumour was confirmed (Snow, Lennard-Jones, Curzon, and Stacey, 1955).

The finding of the duodenal ulcer at operation was considered to explain most, if not all, of the abdominal symptoms of which the patient had been complaining, 
the true nature of which had been obscured by the hepatomegaly and consistently negative barium studies. The patient was now given dietary advice, but, despite gaining weight, continued to have occasional attacks of pain and vomiting about two hours after food over the following months. During this time he was maintained for a period of three months on $1 \mathrm{mg}$. of reserpine daily, and it is interesting in the light of future observations that this treatment did not increase the severity of his flushing attacks as might have been expected had the tumour tissue contained 5-hydroxytryptamine.

In October 1956, after a further exacerbation of his symptoms, he was admitted to hospital for a period of dietetic treatment. In view of other reports on patients with the carcinoid syndrome the urine was examined for histamine and was found to contain about twenty times the normal amount. A fractional test meal was performed and revealed a high concentration of free acid in the resting contents (64 $\mathrm{ml}$. N/10 acid/100 ml. juice); this rose to 94 following a gruel meal with, however, no further significant rise following a subcutaneous injection of histamine. Antihistamines given to the patient at this time were found to reduce but not to abolish flushing attacks. A grade III systolic murmur at the lower end of the sternum was also noted and phlebograms which were carried out confirmed that this was due to tricuspid incompetence. After a period of dietetic treatment the symptoms disappeared and the patient returned home.

In May 1957 bilateral ureteric catheterization was carried out in order to obtain samples from each ureter. The results of this investigation, which first led us to postulate that the tumour was secreting 5-H.T.P. have already been published (Sandler and Snow, 1958). During this admission it was noted that the signs of tricuspid incompetence previously observed had disappeared. A skeletal survey was carried out to exclude the possibility of metastases in bone, which have been reported in other cases (see Sandler and Snow, 1958). No radiological abnormality was found.

The patient was seen at intervals thereafter but on the whole remained fairly well with only occasional brief attacks of pain.

In September 1959, while on a visit to Leeds, he had a severe haematemesis and was admitted to St. James's Hospital, Leeds, under the care of Dr. G. Watkinson. The bleeding continued and an emergency partial gastrectomy of two-thirds extent and of the PolyaMoynihan type was carried out. At operation (Mr. D. B. Feather) an ulcer in the first part of the duodenum was found to be penetrating the pancreas and to have eroded the gastro-duodenal artery. The hepatic findings were similar to those of the previous operation. The patient made a good recovery and six months later had gained a stone in weight and had had no further dyspeptic symptoms.

He was again asymptomatic when seen in January 1961. In the following month, however, he began to experience irregular attacks of abdominal colic which culminated in a severe attack of pain in the left hypochondrium referred to the left shoulder. He vomited a good deal of altered blood and when examined was found to have a tender mass in the left iliac fossa with associated visible peristalsis. He was admitted forthwith to Bolton General Hospital with a diagnosis of pelvic abscess and intestinal obstruction secondary to gastric perforation. He was treated conservatively with fluid replacement, aspiration, and antibiotics, and slowly improved, the abdominal mass and the intestinal obstruction disappeared completely. Unfortunately he then developed severe gastrointestinal bleeding and was transferred to Manchester Royal Infirmary. Laparotomy was performed by Mr. A. R. Anscombe, at which a large perforated anastomotic ulcer and bilateral subphrenic abscesses were found. A total gastrectomy was performed with oesophago-jejunostomy but the patient died later the same day.

\section{MORBID ANATOMY}

The stomach, a small piece of jejunum (from the site of the old partial gastrectomy anastomosis), and several small pieces of metastatic tumour excised from the liver were received fresh in the operating theatre. This material was used for histochemistry, electron-microscopy, and chemical analysis.

The residuum of the stomach (consisting of the cardia and the corpus) showed a deep round chronic ulcer $1 \mathrm{~cm}$. in diameter on the lesser curvature near its upper end. The external surface at this point showed a rounded tumour mass, $3 \mathrm{~cm}$. in diameter, into which the ulcer penetrated. The tumour tissue was of homogeneous, pale grey appearance on section, with a faint yellow tinge. It was not clear whether this tumour mass was a persistence of the original gastric tumour or an infiltrated lymph node which had become adherent to the stomach and had then been penetrated by a primarily non-neoplastic peptic ulcer. Two other nodules of tumour were present along the lesser curvature close by; these were presumably infiltrated lymph nodes. Apart from the ulcer the gastric mucosa appeared normal.

The piece of jejunum showed a line of ulceration along one border.

At necropsy, which was performed 13 hours after death, the body was that of a wasted, middle-aged man, 5 feet 10 inches in height and weighing $40 \mathrm{~kg}$. There was no pigmentation or oedema. The peritoneal cavity showed extensive old upper abdominal adhesions and a small residual left subphrenic abscess. There was a fresh total gastrectomy and oesophago-jejunostomy, the sutures of which were sound. The oesophagus showed gross congestion of the mucosa in the lower third and an ulcer $2.5 \mathrm{~cm}$. in diameter just above the lower end. No tumour, ulceration, or scarring could be seen in the duodenum; and no tumour was found throughout the small intestine, appendix, colon, and rectum.

The liver was considerably enlarged, weighing $3,250 \mathrm{~g}$.; it contained numerous tumour metastases 
up to $7 \mathrm{~cm}$. in diameter, of similar appearance to the gastric tumour. No other metastases were found in lymph nodes or other organs. In particular, the lungs and pancreas were sectioned throughout in serial slices at $\frac{1}{2}$ to $1 \mathrm{~cm}$. intervals, with negative result.

The heart appeared normal (weight $300 \mathrm{~g}$.). There were no valvular abnormalities or mural endocardial thickenings.

HISTOLOGY AND HISTOCHEMISTRY The tumour obtained at operation from the stomach, lesser omental lymph nodes, and liver is of typical carcinoid appearance, consisting of compact groups of epithelial cells with the characteristic, regularly round nuclei and, in some cells, a faint eosinophilic granulation of the cytoplasm. No mitoses are seen. The cell groups lie in a rather scirrhous stroma. Most of the cells are argyrophils; that is, they show numerous, fine, silver-impregnated granules on staining by Bodian's method (Hamperl's modification). None of them from any of the sites sampled shows any of the specific reactions of argentaffin cells; i.e., the Masson-Fontana, alkaline diazo, Lillie's ferricyanide, and Clara's haematoxylin methods all give negative results. Oil red 0 shows lipid globules in occasional tumour cells and the Prussian blue reaction shows haemosiderin granules also in a few tumour cells.

The electron-microscopic findings will be described in detail elsewhere. The tumour cells contained cytoplasmic granules similar to those we have seen in a typical argentaffin carcinoid.

Sections of gastric and jejunal mucosa show a normal distribution and normal staining reactions of the argentaffin and argyrophil cells. The gastric mucosa shows numerous foci of intestinal metaplasia. The jejunum shows subacute peptic ulceration along the stomal margin. The oesophageal ulcer similarly shows subacute peptic ulceration, and the mucosa above it an active subacute diffuse oesophagitis.

The bone marrow (vertebral and mid-femur) shows some normoblastic hyperplasia, presumably produced by loss of blood from the peptic ulcers. The right lung shows early acute bronchopneumonia. The other organs examined all show no significant abnormality, and, in particular, sections of tricuspid, pulmonary, and mitral valve cusps appear entirely normal.

CHEMICAL ASSAY OF URINE AND TUMOUR TISSUE

COLORIMETRIC ESTIMATION OF URINARY 5-HYDROXYINDOLES The separation of 5-H.I.A.A., 5-H.T., and 5-H.T.P. was based on the method used by Udenfriend, Weissbach, and Bogdanski (1957) for the estimation of these substances by spectrophotofluorimetry. Centrifuged urine $(6 \mathrm{ml}$.) was extracted with ether $(2 \times 15 \mathrm{ml}$.) and the ether extract which contained 5-H.I.A.A. was evaporated to dryness in vacuo. The residue was dissolved in water $(5 \mathrm{ml}$.) and aliquots were taken for colorimetric estimation by the nitroso-naphthol method of Macfarlane, Dalgliesh, Dutton, Lennox, Nyhus, and Smith (1956). The extracted urine, mixed with $20 \%$ sodium carbonate solution $(0.5 \mathrm{ml}$.), was shaken with $n$-butanol $(10 \mathrm{ml}$.) to remove 5-H.T. The butanol layer was mixed with petroleum ether $\left(20 \mathrm{ml} .\right.$, b.p. 80 to $100^{\circ} \mathrm{C}$.) and the 5-H.T. was re-extracted into $0 \cdot 2 \mathrm{~N}$ hydrochloric acid $(2 \mathrm{ml}$.). A known fraction of the acid layer was assayed colorimetrically as before. The butanol-extracted urine was made acid with $2 \mathrm{~N}$ sulphuric acid and evaporated to dryness in vacuo. The residue was dissolved in water $(1 \mathrm{ml}$.) and the 5-H.T.P. content was determined colorimetrically. Appropriate standard curves were constructed for the three substances analysed. The method effects a satisfactory separation of the three 5-hydroxyindoles since two-dimensional chromatography (see below) of each extract showed only traces of hydroxyindole other than the expected one.

TWO-DIMENSIONAL PAPER CHROMATOGRAPHY OF UNTREATED URINE The urine (40 to $80 \mu \mathrm{l}$.) was chromatographed on Whatman No. 1 paper for $16 \mathrm{hr}$. in the system isopropanol : ammonia : water $(20: 1: 2)$, followed by $6 \mathrm{hr}$. in the system $n$-butanol:acetic acid:water $(12: 3: 5)$. Dried papers were sprayed with one of the following reagents (Smith, 1960):-

Ehrlich reagent, for indoles

p-Dimethylaminocinnamaldehyde (p-D.M.A.C.), for indoles

Diazotized sulphanilic acid, for phenolic substances and imidazoles

Ninhydrin-pyridine, for amino-acids

Ninhydrin-acetic acid, for tryptamines

TWO-DIMENSIONAL PAPER CHROMATOGRAPHY OF URINE EXTRACT Urine $(1 \mathrm{ml}$.) was diluted with water $(9 \mathrm{ml}$.) and extracted with ether $(2 \times 15 \mathrm{ml}$.). The ether extract, after evaporation in vacuo, was transferred to a paper chromatogram and examined as above. The urine, after adjustment to $p \mathrm{H} 4$, was shaken with charcoal $(0 \cdot 2$ g.) deactivated with $22.5 \%$ stearic acid (cf. Asatoor and Dalgliesh, 1956); the charcoal was filtered off and washed with water $(60 \mathrm{ml}$.) and the aromatic substances were eluted with $60 \mathrm{ml}$. of a mixture of $7.2 \%$ aqueous phenol: acetic acid $(6: 1)$, followed by $30 \mathrm{ml}$. of water. The combined extracts were evaporated to dryness in vacuo and freed from phenol by the addition of water and reevaporation several times before being transferred to a paper chromatogram and run as before.

A similar extract prepared from $6 \mathrm{ml}$. urine was also examined for 5-H.T. and 5-H.T.P. by the colorimetric procedure above.

COLORIMETRIC ANALYSIS OF TUMOUR Weighed amounts of the fresh tumour $(0.5$ to $4 \mathrm{~g}$.) were ground with sand and $40 \%$ trichloracetic acid $(1 \mathrm{ml}$.). After adding water 
$(6 \mathrm{ml}$.$) the mixture was centrifuged and the supernatant$ solution was examined colorimetrically by the method used for urine. In this case ether extraction also removes the trichloracetic acid.

CHROMATOGRAPHIC ANALYSIS OF TUMOUR A supernatant solution obtained as in the last section was extracted with ether $(2 \times 15 \mathrm{ml}$.$) and the evaporated ether extract$ was examined by the usual two-dimensional chromatographic method. The aqueous phase after adjustment to pH 4 was adsorbed onto charcoal and treated as described for urine. After dipping in the p-D.M.A.C. reagent, an estimate of the amount of 5-hydroxyindole in these extracts was made by comparison with standards run at the same time, using the spot-area method. This method has an error of not more than $14 \%$.

ZINC CONTENT OF TUMOUR Zinc was determined by the method of Stewart and Bartlet (1958).

5-H.T.P.-DECARBOXYLASE ACTIVITY OF TUMOUR Decarboxylase activity was determined manometrically by a method based on that of Clark, Weissbach, and Udenfriend (1954). The enzyme was obtained by homogenizing the weighed tissue under investigation with $0 \cdot 1 \mathrm{M}$ phosphate buffer, $p \mathrm{H} 8.0$, and centrifuging. Homogenization was repeated several times and the supernatants were combined.

Warburg flasks (20 to $25 \mathrm{ml}$.) were set up as follows:-

Main compartment Enzyme extract (1 ml.); M phosphate buffer, $p H \quad 8.0(0.5 \mathrm{ml}$.); $0.012 \mathrm{M}$ sodium fluoride solution $(0 \cdot 2 \mathrm{ml}$.); pyridoxal phosphate solution (10 $\mu \mathrm{g}$. in $0.1 \mathrm{ml}$.)

First side-arm $0.2 \%$ DL-5-H.T.P. solution $(0.5 \mathrm{ml}$.) or water $(0.5 \mathrm{ml}$.) for blank determination

Second side-arm $2 \mathrm{~N}$ sulphuric acid (0.4 ml.)

After equilibration at $37^{\circ} \mathrm{C}$. in nitrogen, the manometer reading was noted. The contents of the first sidearm were added to the main compartment and incubation was continued for one hour with shaking, after which time the reaction was stopped and carbon dioxide fully released by adding the sulphuric acid. After a further 15 min., the final reading was noted. The activity, corrected for blanks, was expressed as $\mu \mathrm{l} . \mathrm{CO}_{2} / \mathrm{hr} . / \mathrm{g}$. fresh tissue.

\section{RESULTS}

Figures reported are corrected for losses occurring during the fractionation or estimation.

URINE ANALYSIS The major 5-hydroxyindoles found were 5-H.I.A.A., 5-H.T., and 5-H.T.P. The excretion of the three substances is shown in Table $I$, which includes a comparison with the earlier figures of Sandler and Snow (1958) in which the figure for 5-H.T.P. was derived from the difference between total 5-hydroxyindole excretion and the sum of 5-H.I.A.A. and 5-H.T. excretions. The figures for the individual 5-hydroxyindoles obtained colorimetrically from untreated urine and the charcoalextract of urine were identical. This later urine
TABLE I

URINARY EXCRETION OF 5-HYDROXYINDOLES

\begin{tabular}{lccc} 
Compound & $\begin{array}{l}\text { Present Series } \\
(\mathrm{mg} / 24 \mathrm{hr} .)\end{array}$ & $\begin{array}{l}\text { Figures from Sandler and Snow } \\
(1958)(\mathrm{mg} . / 24 \mathrm{hr} .)\end{array}$ \\
\hline 5-H.T.P. & 37 & 49 & 34 \\
5-H.T. & 23 & 18 & 24 \\
5-H.I.A.A. & 46 & 43 & 59 \\
Total & 106 & 110 & 117
\end{tabular}

analysis shows a similar pattern to that noted earlier. The interesting features are the high excretion of 5-H.T.P. and the appreciable quantities of 5-H.T. as well as the high figure for 5-hydroxyindole-3-acetic acid.

The urine also contained several amino-acids, some of which were poorly separated on the chromatographic system used. Ninhydrin-positive material was present in the regions occupied by glycine and alanine, and histidine was just detectable. The excretion of these amino-acids is probably within the normal range. There was, however, a welldefined spot for tryptophan and comparison of that spot with tryptophan standards run in the same system indicates a 24-hour excretion of about $100 \mathrm{mg}$., an abnormally high figure. A weak reaction for histamine was noted but this amine was not detected with any certainty. Sandler and Snow reported a raised level of histamine in previous urines from this patient.

In addition to the major indolic excretion products, several other Ehrlich-positive spots of lesser intensity were present on the chromatograms. These probably represent minor metabolic products of the 5-hydroxyindole series but were not further characterized.

Since increased excretion of catecholamine metabolites has been reported in cases of the carcinoid syndrome (von Studnitz, 1959), the same 24-hour specimen of urine was examined by Mr. M. Bell of the Clinical Laboratory, Manchester Royal Infirmary. No increased excretion of hydroxymethoxymandelic acid was found.

5-HYDROXYINDOLES IN TUMOUR TISSUE The lymph node metastasis examined by the colorimetric procedure gave a positive result for 5-H.T.P. only (Table II); 5-H.I.A.A. and 5-H.T. could not be detected colorimetrically. Chromatographic examination of the 5-H.T.P. fraction showed that this substance was the only detectable 5-hydroxyindole present. The more sensitive paper chromatographic method applied to the lymph node metastasis confirmed the figure for 5-H.T.P. and revealed the presence of 5-H.T. in small amounts. The only other indole found in these extracts was tryptophan which was present to the extent of about 10 to $15 \mu \mathrm{g}$. per $\mathrm{g}$. fresh tissue. It is possible that this was derived 
TABLE II

5-HYDROXYINDOLES IN TUMOUR TISSUE

5- $H$ T P

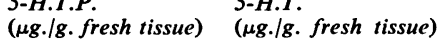

\begin{tabular}{|c|c|c|}
\hline $\begin{array}{l}\text { Argyrophil carcinoid (this } \\
\text { Hepatic metastasis }\end{array}$ & case) & $\begin{array}{c}\text { Not detectable } \\
(<0.3)\end{array}$ \\
\hline Lymph node metastasis & $5 \cdot 4$ & $0 \cdot 2$ \\
\hline $\begin{array}{l}\text { Argentaffin carcinoid of } \\
\text { ileum }\end{array}$ & $\begin{array}{c}\text { Not detectable } \\
(<1)\end{array}$ & 1,420 \\
\hline
\end{tabular}

from tissue fluid in the tumour. The average level of tryptophan in plasma (and presumably extracellular fluid) is $13 \mu \mathrm{g} . / \mathrm{ml}$.

The same chrcmatographic method applied to the hepatic metastasis revealed amounts of 5-H.T.P. and tryptophan similar to those in the lymph node tumours. There was no detectable 5-H.T. in the small amount of tissue available for analysis and no other indoles were present.

In Table II the figures obtained for the two metastases are compared with the figures for a typical argentaffin carcinoid tumour of the ileum investigated in this laboratory by the same methods. The very low 5-H.T. content of the argyrophil tumour contrasts with the high figure for 5-H.T. in the argentaffin tumour. Similar levels of 5-H.T. in argentaffin tumours have been described on a number of occasions by other workers. Figures for 5-H.T.P. content of argentaffin tumours are not available in the literature but, as shown in Table II, there is an obvious difference between the two types of tumour. The amount of tissue available from the argentaffin carcinoid was small, which precluded detection of submicrogram amounts of 5-hydroxytryptophan.

ZINC CONTENT IN TUMOUR TISSUE The zinc content of the lymph node metastasis was $240 \mu \mathrm{g}$. $/ \mathrm{g}$. dry weight. This figure is much lower than the figures of $715,2,010$, and $2,380 \mu \mathrm{g} . / \mathrm{g}$. dry tissue reported for argentaffin intestinal carcinoid tumours by Feyrter (1956), but is similar to the level we have found (206) in an ileal argentaffin carcinoid. The figures in both of these tumours are a little higher than the figures found by us for the following tissues: normal jejunal mucosa (96), bronchial carcinoma (88), lymph node metastasis of bronchial carcinoma $(120,149)$. Similar figures were obtained by Heath (1942) for normal stomach and duodenum (130), bronchial carcinoma (73-102), and secondary carcinoma in liver (140). Feyrter (loc. cit.) has reported a high zinc content (935) in a bronchial carcinoid of the argyrophil type; but we have found a much lower level (88) in a similar tumour.
5-H.T.P.-DECARBOXYLASE ACTIVITY IN TUMOUR TISSUE It was not possible to detect any decarboxylase activity in the lymph node metastasis; the activity was certainly less than $10 \mu \mathrm{l} / \mathrm{g}$./hr. By contrast, a typical argentaffin ileal carcinoid had an activity of $210 \mu \mathrm{l}$./g./hr. Normal guinea-pig gastric mucosa had an activity of 94 to $108 \mu \mathrm{l}$./g./hr. and guinea-pig kidney $160 \mu \mathrm{l} . / \mathrm{g} . / \mathrm{hr}$. Giarman, Green, Green, and Paasonen (1957) investigated an argentaffin carcinoid tumour of the appendix by a related method and showed that the tumour had a decarboxylase activity equivalent to $107 \mu \mathrm{l}$./g./hr., a figure 35 times that of normal appendiceal tissue; the concentration of 5-H.T. in this tumour was 1,000 times that of normal appendix.

GASTRIN ASSAY IN TUMOUR TISSUE A sample of gastric juice obtained during life and tissue from a lymph node metastasis were examined by Professor A. A. Harper, of the Department of Physiology, University of Durham, who reports that he found no gastrin activity in either.

HISTAMINE ASSAY IN TUMOUR TISSUE Tumour tissue was assayed for histamine by Dr. H. J. Lake, of the Department of Physiology, University of Durham; two assays gave figures of 102 and $105 \mu \mathrm{g}$. of histamine base per gram of moist tissue. These values are about ten times that reported by Trach, Code, and Wangensteen (1944) for normal human fundic mucosa.

\section{DISCUSSION}

In the earlier report of this case, Sandler and Snow (1958) suggested that it belonged to a rare variant group of carcinoid tumours which produced 5-H.T.P. This has now been confirmed by the positive identification and assay of this substance both in the urine and the tumour tissue.

5-Hydroxytryptophan cannot be found in normal tissues or in typical carcinoid tumours presumably because, in the metabolism of tryptophan to 5-H.T., hydroxylation is the rate-limiting reaction: widely available and freely active decarboxylase converts the 5-H.T.P. to 5-H.T. as soon as it is formed (Udenfriend, 1960). We consider that the variant behaviour of the tumour here reported results from a virtual absence of decarboxylase activity in the tumour cells, so that 5-H.T.P. accumulates in and is liberated from them, while they form little or no 5-H.T. The 5-H.T.P. liberated into the blood will in part be converted to 5-H.T. by the decarboxylase present in other normal tissues; but a considerable proportion will presumably reach the kidneys unchanged. Some is excreted as 5-H.T.P., but an appreciable amount is 
decarboxylated in the kidney itself and appears in the urine as 5-H.T. The kidney is known to be rich in 5-H.T.P.-decarboxylase activity (Clark et al., 1954). The 5-H.T. produced by extrarenal decarboxylation will be oxidized by the widespread amineoxidase so producing 5-H.I.A.A. which is then excreted. The urine analysis suggests that renal and extrarenal decarboxylation occur at approximately equal rates.

The appearance of increased amounts of tryptophan in the urine might be due to competition between 5-H.T.P. and tryptophan for a common pathway of reabsorption in the renal tubule. This view, however, must remain speculative until more is known about the renal tubular mechanism involved.

It is probably justifiable, as Sandler and Snow suggested, to associate the variant biochemical behaviour of this tumour with the fact that its cells are argyrophil and not argentaffin. Carcinoid tumours reported as producing 5-H.T. have usually been argentaffin; unfortunately in many case reports the histochemistry has been inadequate and a clear distinction has not always been made between argyrophilia and argentaffinia. In the present case freshly fixed tumour tissue was available by biopsy on three occasions: in 1955, in 1959 (by the kindness of Dr. W. Goldie of St. James' Hospital, Leeds), and at the final operation. On all occasions the tumour cells were argyrophil but not argentaffin. The evidence is now strong that the argentaffin reaction is associated with the presence of 5-H.T. in the cell (for references see Campbell, 1959). The absence of argentaffinia here accords, therefore, with the failure of the tumour to produce 5-H.T. It is not justifiable, however, to assume that argyrophil cells necessarily form or contain 5-H.T.P. Many carcinoids in various sites have been reported as argyrophil (Lillie and Glenner, 1960) but in very few of these has 5-H.T.P. been found or looked for. Appajee and Campbell (unpublished data) have found that guinea-pigs on a diet low in tryptophan show an increase of argyrophil cells in the alimentary tract, making it unlikely that argyrophilia necessarily indicates a content of 5-H.T.P. and argyrophil granulation is found in cells, such as the $\alpha$ cells of the pancreatic islets in some species (Hamperl, 1952) which have no overt association with hydroxyindole metabolism.

As noted above, 5-H.T.-producing tumours are usually argentaffin, and when they are reported as argentaffin-negative some suspicion is justified since freshly fixed tissue is essential to demonstrate argentaffinia and the staining methods are not always properly applied. Occasional reliable reports, however, suggest that an apparently purely argyro- phil tumour may contain notable amounts of 5-H.T. (Thorson, 1958), and Williams and Azzopardi (1960) have recently reported an oat-cell carcinoma of bronchus which was neither argyrophil nor argentaffin but which contained 5-H.T. and produced the carcinoid syndrome so that the relationship of argyrophil and argentaffin granules to the various stages of 5-H.T. metabolism is not yet entirely clear cut. One can say, however, that with an argentaffin carcinoid one may expect 5-H.T. to be produced; and that with a carcinoid that is reliably shown to be purely argyrophil it is worth while looking, though much less confidently, for evidence of 5-H.T.P. production.

The prominence of peptic ulceration in this case is notable. At one time or another ulcers were found in oesophagus, stomach, duodenum, and stomal jejunum. The very high acid secretion suggested an affinity with the Zollinger-Ellison syndrome of peptic ulceration associated with pancreatic islet-cell tumours of non- $\beta$ cell type. High levels of gastrinlike activity have been found in these tumours (Gregory, Tracy, French, and Sircus, 1960; Marks, Selzer, Louw, and Bank, 1961; Grossman, Tracy, and Gregory, 1961) and it seemed possible that the tumour in our case might be liberating gastrin as well as 5-H.T.P. The $\alpha$ cells of the islet are, in some species, argyrophil (Hamperl, 1952) and tumours of these cells might perhaps have something in common with a tumour such as the present one. However, Professor Harper's assay of the tumour for gastrin was negative.

It is tempting to believe that the increased production of histamine played a part in the pathogenesis of the ulcers. This may well be so. But a tendency to peptic ulceration appears to be a significant feature of the malignant carcinoid syndrome (MacDonald, 1956), and, as histamine assays have been performed in few if any of these cases, the pathogenetic factor remains uncertain.

We gratefully acknowledge the help given us by Professor A. A. Harper, Dr. H. J. Lake, and Mr. M. Bell, who carried out the assays of gastrin, histamine, and catecholamine metabolites respectively. We are grateful also to Dr. H. T. Howat, Mr. A. R. Anscombe, Dr. G. Watkinson, Mr. D. B. Feather, and Dr. W. Goldie for giving us access to their records. One of us (D.S.P.) acknowledges the support of the Medical Research Council, from whom he holds a research scholarship.

\section{REFERENCES}

Asatoor, A.. and Dalgliesh, C. E. (1956). The use of deactivated charcoals for the isolation of aromatic substances. J. chem. Soc., pp. 2291-2299.

Campbell, A. C. P. (1959). The pathological relationships of 5-hydroxytryptamine. In Modern Trends in Pathology, edited by Collins, D. H., pp. 231-247. Butterworth, London. 
Clark, C. T., Weissbach, H., and Udenfriend, S. (1954). 5-Hydroxytryptophan decarboxylase: preparation and properties. $J$. biol. Chem., 210, 139-148.

Feyrter, F. (1956). Zur Biochemie des Darmkarzinoids. Zbl. allg. Path. path. Anat., 95, 151-156.

Giarman, N. J., Green, V. S., Green, J. P., and Paasonen, M. K. (1957). Pharmacological and biochemical study of a carcinoid tumor. Proc. Soc. exp. Biol. (N.Y.), 94, 761-763.

Gregory, R. A., Tracy, H. J., French, J. M., and Sircus, W. (1960). Extraction of a gastrin-like substance from a pancreatic tumour in a case of Ellison-Zollinger syndrome. Lancet, 1, 1045-1048.

Grossman, M. I., Tracy, H. J., and Gregory, R. A. (1961). ZollingerEllison syndrome in a Bantu woman, with isolation of a gastrin-like substance from the primary and secondary tumors. II. Extraction of gastrin-like activity from tumors. Gastroenterology, 41, 87-91.

Hamperl, H. (1952). Uber argyrophile Zellen. Virchows Arch. path. Anat., 321, 482-507.

Heath, J. C. (1942). Concentration of zinc in normal and malignant tissues. Brit. Emp. Cancer Campgn, 19th Ann. Rep.-1942, p. 46.

Lillie, R. D., and Glenner, G. G. (1960). Histochemical reactions in carcinoid tumors of the human gastrointestinal tract. Amer. J. Path., 36, 623-651.

MacDonald, R. A. (1956). A study of 356 carcinoids of the gastrcintestinal tract. Amer. J. Med., 21, 867-878.

Macfarlane, P. S., Dalgliesh, C. E., Dutton, R. W., Lennox, B., Nyhus, L. M., and Smith, A. N. (1956). Endocrine aspects of argentaffinoma with special reference to the use of urinary 5-hydroxyindoleacetic acid estimations in diagnosis. Scot. med. J., 1, 148-155.
Marks, I. N., Selzer, G., Louw, J. H., and Bank, S. (1961). ZollingerEllison syndrome in a Bantu woman, with isolation of a gastrin-like substance from the primary and secondary tumors. I. Case report. Gastroenterology, 41, 77-86.

Sandler, M., and Snow, P. J. D. (1958). An atypical carcinoid tumour secreting 5-hydroxytryptophan. Lancet, 1, 137-139.

Smith, A. N., Nyhus, L. M., Dalgliesh, C. E., Dutton, R. W., Lennox, B., and Macfarlane, P. S. (1957). Further observations on the endocrine aspects of argentaffinoma. Scot. med. J., 2, 24-38.

Smith, I. (1960). Chromatographic and Electrophoretic Techniques. 2nd ed., Vol. 1, pp. 193-196. Heinemann, London.

Snow, P. J. D., Lennard-Jones, J. E., Curzon, G., and Stacey, R. S (1955). Humoral effects of metastasising carcinoid tumours. Lancet, 2, 1004-1009.

Stewart, J. A., and Bartlet, J. C. (1958). Determination of zinc and separation from ashed biological material. Analyt. Chem., 30, 404-409.

Studnitz, W. von (1959). On the excretion of 3-methoxy-4-hydroxymandelic acid in patients with serotonin producing tumours. Scand. J. clin. Lab. Invest., 11, 309-310.

Thorson, Å. H. (1958). Studies on carcinoid disease. Acta med. scand., 161, suppl. 334, pp. 1-132.

Trach, B., Code, C. F., and Wangensteen, O. H. (1944). Histamine in human gastric mucosa. Amer. J. Physiol., 141, 78-82.

Udenfriend, S. (1960). Amine metabolism and its pharmacological implications. Neuropharmacology, Trans. 5th Conf., 1959, edited by Abramson, H. A., pp. 11-130. Josiah Macy, Jr. Foundation, New York.

- - Weissbach, H., and Bogdanski, D. F. (1957). Increase in tissue serotonin following administration of its precursor 5-hydroxytryptophan. J. biol. Chem., 224, 803-810.

Williams, E. D., and Azzopardi, J. G. (1960). Tumours of the lung and the carcinoid syndrome. Thorax, 15, 30-36. 